\title{
EXPLICAÇÕES COMPORTAMENTAIS PARA POLÍTICAS DE REDISTRIBUIÇÃO DE RENDA: UMA REVISÃO DOS MODELOS E EVIDÊNCIAS ${ }^{1}$
}

\author{
Willian Boschetti Adamczyk \\ Mestre em Economia no Programa de Pós-Graduação em Economia da Pontifícia Universidade Católica do Rio \\ Grande do Sul - PPGE/PUCRS. \\ Endereço: Rua Duque de Caxias, 16 - Centro - Erechim / RS. \\ CEP 99700-274 E-mail: willianadamczyk@yahoo.com.br
}

\section{Ely José de Mattos}

Professor do Programa de Pós-Graduação em Economia da Pontifícia Universidade Católica do Rio Grande do Sul - PPGE/PUCRS.

Endereço: PPGE/PUCRS, Av. Ipiranga, 6681 - Prédio 50, andar 11 - Partenon - Porto Alegre / RS

CEP: 90619-900 E-mail: ely.mattos@ pucrs.br

\section{RESUMO:}

Esta revisão bibliográfica apresenta a evolução dos modelos que explicam os diferentes níveis de redistribuição de renda nos países da OECD e América Latina, considerando o papel das crenças sociais da população. As teorias têm início com a ideia do eleitor decisivo e da regra da maioria, exposto no modelo de Meltzer \& Richard (1981), além das explicações políticas, econômicas e comportamentais de Alesina et al. (2001). Desenvolvimentos posteriores de Alesina \& Glaeser (2004), Alesina \& Angeletos (2005) e Figueiredo (2012) incorporam o papel das crenças sociais na sorte como elemento fundamental da redistribuição de renda e da percepção sobre a desigualdade de oportunidades. Considera-se que as evidências empíricas contrastantes estimulam o desenvolvimento de novos modelos que incorporem as crenças sociais como determinantes para a redistribuição de renda.

PALAVRAS-CHAVE: Desigualdade, Crenças Sociais, Redistribuição de Renda

\begin{abstract}
:
This bibliographic revision presents the evolution of the models that explain the the different levels of income redistribution in OCDE and Latin American countries, considering the role of social beliefs of population. The theories begins with the idea of a decisive voter and majority rule, as exposed in Meltzer \& Richard (1981), going through political, economic and behavioral explanations given by Alesina et al. (2001). Latter developments of Alesina \& Glaeser (2004), Alesina \& Angeletos (2005) and Figueiredo (2012) embrace the social belief in the role of luck as a fundamental element of the income redistribution and the perception about inequality of opportunity. It is considered that the contrasting empirical evidences foster the development of new models that incorporate social beliefs as determinants of income redistribution.
\end{abstract}

KEYWORDS: Inequality, Social Beliefs, Income Redistribution

\footnotetext{
${ }^{1}$ Trabalho premiado no IV Seminário de Jovens Pesquisadores em Economia e Desenvolvimento.
} 


\section{INTRODUÇÃO}

A literatura econômica oferece diferentes explicações para a diversidade e intensidade de políticas de redistribuição de renda adotadas por cada país. A disparidade entre os países da OCDE e da América Latina, por exemplo, pode derivar de diferentes alocações de recursos em gastos sociais e opções de políticas públicas.

Segundo dados da Comissão Econômica Para a América Latina e Caribe (CEPAL), os países membros da OCDE alocavam, em média, 8\% do PIB em gastos sociais nos anos 1960, passando para uma média de 17\% nos anos 2000. Enquanto isso, o grupo de países da América Latina passou de 7\% em 1960, para 21\% do PIB nos anos 2000. Enquanto no grupo desenvolvido o percentual apenas duplicou, os países latinos viram seus gastos sociais triplicar como proporção do PIB.

Frente a esse cenário diverso de alocações de recursos em gastos sociais, diferentes modelos buscam explicar o fenômeno, considerando a evolução dos modelos de equilíbrio geral mais simples até a incorporação de variáveis comportamentais e de crenças sociais.

O primeiro modelo apresentado, de Meltzer \& Richard (1981), investiga o comportamento dos indivíduos sob um cenário de sufrágio universal e regra da maioria. Isso é feito através de um modelo que considera que as preferências por redistribuição são influenciadas diretamente pela posição relativa do eleitor mediano em relação à renda média da sociedade.

Segundo os autores, o eleitor demandará maior distribuição quando a sua renda estiver abaixo da renda média da sociedade, o que o colocaria na posição de receptor de renda. Caso contrário, demandaria uma menor distribuição de renda, estando na posição de doador de renda. Assim, os autores afirmam que políticas de redistribuição de renda seriam mais demandadas em sociedades com maiores desigualdades de renda.

A partir disso, autores buscam construir modelos que incorporem o papel das crenças sociais através de variáveis comportamentais para explicar a demanda por diferentes níveis de redistribuição de renda (ALESINA et al., 2001; ALESINA \& ANGELETOS, 2005; BÉNABOU \& TIROLE, 2006).

A interação entre crenças sociais e políticas de bem-estar podem levar a múltiplos equilíbrios para a distribuição em uma sociedade. Segundo Alesina \& Angeletos (2005), se uma sociedade acredita que o esforço individual determina a renda, e que todos têm o direito de se aproveitar dos frutos de seus esforços, essa sociedade escolherá um baixo nível de redistribuição através de baixo nível de impostos.

No equilíbrio, o esforço será alto e o papel da sorte será limitado, assumindo assim que os resultados obtidos através do mercado serão relativamente justos. Além das crenças sobre sorte ou esforço como determinante da renda, a heterogeneidade racial e o sistema político de cada sociedade influenciam o resultado final da distribuição.

Por fim, é apresentado um modelo proposto por Figueiredo (2012) a fim de melhor explicar os determinantes por distribuição de renda nos países da América Latina. Segundo o autor, os modelos anteriores não são os mais adequados para esse continente pois as percepções das pessoas sobre as oportunidades oferecidas em cada país são diferentes daquelas percebidas em países desenvolvidos. 
Através da exposição dos modelos comportamentais de distribuição de renda, busca-se tornar mais clara a compreensão da evolução e dos resultados encontrados por esses modelos para as diferentes sociedades.

\section{MODELOS DE REDISTRIBUIÇÃO DE RENDA}

\subsection{O MODELO DE ESCOLHA RACIONAL}

O modelo de escolha racional das dimensões do governo foi desenvolvido por Allan Meltzer \& Scott Richard em 1981. A hipótese dos autores implica que o tamanho do governo depende da relação entre a renda média da sociedade e a renda do eleitor decisivo.

Usando um modelo de equilíbrio no qual as únicas funções do governo são a taxação e redistribuição, mostraram que o tamanho do governo é determinado pela escolha maximizadora do bem-estar do eleitor decisivo. O eleitor decisivo pode ser um ditador, um rei absolutista, ou o membro marginal de um conselho.

Em uma sociedade que adota o sufrágio universal e regra da maioria, as preferências do eleitor mediano serão decisivas na escolha do partido ou representante vencedor. Esse modelo considera que os eleitores não sofrem de "ilusão fiscal" e não são míopes. Isso significa que eles sabem que o governo deve extrair recursos da sociedade a fim de pagar pela redistribuição.

Os autores se concentram na demanda por redistribuição e não consideram quaisquer "bens públicos" provisionados pelo governo. Também retornam a uma antiga tradição que associa o tamanho do governo, medido por impostos e gastos, com dois fatores: a abrangência da concessão e a distribuição de riqueza (propriedade).

A partir de estudos de distribuição de renda que mostram que a distribuição é assimétrica para a direita, Meltzer \& Richard (1981) mostram que a renda média da sociedade ficaria acima da renda do eleitor decisivo, a renda mediana. Essa forma acentuada de desigualdade de renda explicaria a demanda crescente por redistribuição, através do maior papel do governo na economia.

Qualquer regra de votação que concentra votos abaixo da média oferece um incentivo para redistribuição de renda financiada por impostos nas rendas que são relativamente mais altas. Isso abrange um maior número de eleitores situados abaixo da renda média da sociedade, o que aumenta os votos por redistribuição e, assim, aumenta o tamanho do governo em forma de gastos sociais.

Gastos governamentais e impostos tem crescido relativamente ao produto na maioria dos países com governos eleitos democraticamente nos últimos 30 anos ou mais. Segundos os autores, um maior tamanho relativo do governo parece ser independente do sistema de orçamento ou de impostos, a extensão da burocracia ou outros fatores institucionais frequentemente relacionados.

\subsection{MOBILIDADE SOCIAL E INCERTEZA DE RENDA}

Não satisfeitos com a explicação de Meltzer \& Richard (1981) para a distribuição através das preferências do eleitor mediano, um modelo é desenvolvido por Alesina et al. 
(2001). Os autores buscam investigar os determinantes para redistribuição de renda no que concerne à mobilidade social em cada sociedade e a incerteza de renda esperada pelos indivíduos.

Segundo os autores, existem duas possíveis explicações para as diferenças de demanda por um estado de bem-estar social entre Estados Unidos e Europa. Primeiro, é possível que o eleitor mediano norte-americano espere maiores níveis de renda futura em comparação com o eleitor mediano europeu. Segundo, um número maior de choques exógenos vividos pelos europeus pode levá-los a demandar mais redistribuição como um fator de redução de riscos.

Os indivíduos com maior crescimento de renda esperada são mais passíveis de se opor à redistribuição. Assim, norte-americanos deveriam encontrar maiores probabilidades de crescimento futuro na renda a fim de desejar menos políticas redistributivas nos Estados Unidos em comparação à Europa.

Alesina et al. (2001) usa dois conjuntos de evidências para responder a essa questão: dados de mobilidade de renda verificada e questionários sobre mobilidade. As surveys oferecem um panorama das crenças individuais que poderiam determinar o comportamento de votação.

Os autores recorrem a dados da World Values Survey (WVS), projeto de pesquisa global sobre crenças e valores sobre política, religião, meio ambiente, entre outras. Na WVS, uma das questões busca investigar as crenças sobre quais as chances, na opinião dos respondentes, que os pobres teriam de escapar da pobreza. Para essa questão, $71 \%$ dos norteamericanos responderam positivamente, contra apenas $40 \%$ dos europeus.

Porém, essa questão não oferece respostas diretas sobre as perspectivas de crescimentos na renda dos eleitores medianos. Para isso, Gottschalk e Spolaore (2002) constroem uma matriz de transição de renda ao longo de 15 anos entre Estados Unidos e Europa. As diferenças não são significativamente contrastantes, e as mudanças nos Estados Unidos são muito similares as da Alemanha. Ainda assim, se a mobilidade é importante e norte-americanos acreditam que existe maior chance de melhorias em sua posição, é mais provável que haverá maior aversão à redistribuição nos Estados Unidos. Para entender o fenômeno das diferentes demandas por redistribuição, Alesina et al. (2001) incluem três proposições em seu modelo.

A primeira proposição busca capturar o papel do poder político e altruísmo, identificando quais fatores aumentariam o poder político dos pobres, aumentando a redistribuição. Pode-se inferir que, baseado nessa proposição, maiores níveis de redistribuição de renda estão associados com maior representação política dos pobres, e menores níveis estão relacionados com uma sociedade menos altruísta.

Incorporando a hipótese de redistribuição egoísta e regra da maioria, não haveria altruísmo e o nível de redistribuição é determinado pelas preferências do eleitor mediano. A probabilidade dessa redistribuição acontecer dependeria das perdas sociais causadas por altos níveis de impostos e da assimetria de renda na sociedade.

Se a renda futura esperada pelo eleitor mediano for superior à renda do período presente, a redistribuição tende a cair. O mesmo efeito se verificaria se os choques de renda para o eleitor mediano são positivos. Caso o eleitor mediano enfrente médias negativas nos choques de renda, o desejo por redistribuição será decrescente. 


\subsection{REDISTRIBUIÇÃO DE RENDA: EXPLICAÇÕES ECONÔMICAS, POLÍTICAS E COMPORTAMENTAIS.}

Alesina et al. (2001) exploraram possíveis explicações empíricas para responder à questão-título do artigo “Why Doesn't the United States Have a European-Style Welfare State?". Essas explicações procuram prover evidência para os resultados e proposições que eles obtiveram de seu modelo. Assim, seu foco é na Europa e Estados Unidos, e suas possíveis explicações dividem-se em econômicas, políticas e comportamentais.

\subsection{1 - Explicações Econômicas}

As explicações econômicas começam com a análise da desigualdade antes dos impostos. De acordo com as proposições, a redistribuição será maior na Europa caso sua desigualdade antes dos impostos seja maior, ou a sua distribuição de renda seja mais assimétrica do que nos Estados Unidos.

Porém, o coeficiente de Gini antes dos impostos é maior para os Estados Unidos (38,5 contra 29,5). Também, em termos de assimetria, os $20 \%$ das pessoas com maior renda nos Estados Unidos ganham 43,5\% dos dólares antes dos impostos, contra uma média de 37,1 para a União Europeia.

Segundo os autores, a explicação baseada na desigualdade de renda antes dos impostos falha por duas razões. Primeiro, pessoas pobres podem não ter poder político suficiente para provocar maior redistribuição nos países com elevada desigualdade de renda; segundo, o coeficiente de Gini medido antes dos impostos não considera outras políticas afetando a desigualdade e pode superestimar a real desigualdade de renda real nos Estados Unidos.

Outra possível explicação sugerida por Alesina et al. (2001) se refere ao custo da redistribuição. Se a taxação criasse menos distorções na Europa, haveria maior redistribuição, similarmente, se a redistribuição fosse vista com menores custos administrativos.

Porém, segundo os autores, a taxação europeia não é mais efetiva que a taxação norteamericana. A pesquisa WEF Global Competitiveness Report (1996) perguntou a líderes empresariais sobre a adequação aos impostos em seus países, e os resultados indicaram uma pontuação de 4.47 (de 5) para os Estados Unidos contra uma média de 3.5 para os países da União Europeia. Além disso, não há evidência que os europeus possuam taxas que provoquem menos distorções.

\subsection{2 - Explicações Políticas}

Em busca de explicações políticas, a primeira variável analisada por Alesina et al. (2001) é o sistema eleitoral. Trabalhos de Ku \& Salmon (2012), Milesi-Ferretti et al. (2001) e Persson \& Tabellini (2000) testam a hipótese de que "em sistemas majoritários caracterizados por distritos geograficamente segmentados, no qual cada distrito escolhe um representante, o governo eleito irá favorecer o gasto em programas que podem ser geograficamente orientados" (ALESINA et al., 2001, p. 30).

Apesar dos diferentes dados utilizados pelos autores, os seus resultados são consistentes com a hipótese de que programas universais de transferência de renda devem ser maiores em países com sistemas eleitorais mais proporcionais. 
A segunda variável analisada por Alesina et al. (2001) é a história política. Para Skocpol (1992), os Estados Unidos e os países europeus tiveram um sistema político muito similar entre si no mesmo período, desde o século XIX.

Um sistema de seguridade social universal não foi desenvolvido, apesar das tentativas de alguns policymakers devido a razões decorrentes da constituição dos Estados Unidos, que protege a propriedade privada de possíveis excessos da democracia, rejeitando qualquer legislação vista como desfavorável aos negócios.

Além disso, as cortes têm um papel fundamental no sistema legal. "Dada a relativa falha de provisão de bem-estar nos Estados Unidos no fim do século XIX, a assistência social tomou um rumo em direção a iniciativas privadas que permeiam a sociedade norte-americana até os dias de hoje" (ALESINA et al., 2001, p. 35).

Segundo Alesina et al., aqueles que imigraram para os Estados Unidos na sua formação eram menos avessos ao risco e mais sensíveis a incentivos do que aqueles que permaneceram na Europa, o que alimenta um sentimento "anti-estatista" e desestimula o desenvolvimento maior de um estado de bem-estar social.

Um ponto complementar se refere a menor densidade populacional nos Estados Unidos. Alesina et al. (2001) encontraram uma correlação positiva entre a densidade populacional e redistribuição nos países da OCDE. O sistema descentralizado dos Estados Unidos pode também estar relacionado ao impacto de divergências locais como ameaça ao poder central, diferentemente da França, por exemplo. Assim, Alesina et al. (2001) concluem que de acordo com as explicações políticas, todas as regras são de alguma forma endógenas.

A grande diferença entre os Estados Unidos e a Europa nessa questão é a sua estabilidade política. Eles encontram uma correlação significante entre o ano da última constituição do país e sua redistribuição. Em uma amostra de dezesseis países da OCDE, a correlação entre o nível de gasto social e o ano da constituição mais recente é de 0,52. Finalmente, o excepcionalismo norte-americano parece ser motivado pelos demais fatores políticos do que diferenças nos sistemas eleitorais.

\subsection{3 - Explicações Comportamentais}

Alesina et al. (2001) também explorou explicações comportamentais a procura de razões para que o eleitor mediano demandasse redistribuição. Para isto, foram consideradas duas hipóteses, uma incorporando o Altruísmo Recíproco e outra baseada no Preconceito Racial.

A teoria que incorpora o Altruísmo Recíproco se relaciona ao bem-estar através da consideração de que aqueles que são pobres e recebem renda dos contribuintes estão burlando o sistema. Procurando explicar se essa percepção difere nos Estados Unidos e Europa, Alesina et al. (2001) utilizam respostas para questões da World Values Survey.

Primeiro, se as pessoas são pobres por causa de imperfeições da sociedade ou porque são preguiçosos, para a qual $70 \%$ dos Americanos responderam Preguiça enquanto $70 \%$ dos Alemães Orientais responderam o contrário.

A segunda questão abrange a visão de se os pobres estão presos na pobreza. Para $71 \%$ dos Americanos, os pobres têm condições de sair da pobreza através do esforço, contra apenas $42 \%$ dos Europeus. 
Quando são relacionadas essas respostas à questão de se o esforço ou sorte determinam a renda e o gasto social, eles encontram uma correlação positiva, indicando que quanto mais pessoas acreditarem que a sorte influencia no sucesso, maior o gasto social do país.

Por outro lado, a teoria de Discriminação Racial, formulada por Gary Becker (1957), assume que pessoas tendem a identificar os grupos a partir de conceitos de raça, na qual são mais simpáticas com pessoas semelhantes e mais hostis com pessoas que pertençam a outra raça.

Essa crença racial tem importantes consequências de contexto político, particularmente nos Estados Unidos, onde a raça historicamente tem sido um importante elemento para a identificação em grupo. "Americanos pensam nos pobres como membros de um grupo diferente do deles, enquanto europeus pensam nos pobres como pertencentes ao seu mesmo grupo" (ALESINA et al. 2001, pg. 43).

O isolamento social ou geográfico também pode ter um papel nessas questões, representando uma menor simpatia dos não pobres com relação aos pobres isolados. Os autores supõem uma diferença entre o apoio por redistribuição quando as pessoas identificam os beneficiários como pertencendo a sua própria raça.

Os autores sugerem que os não pobres teriam maior preferência por redistribuição quando se identificam com os pobres, e menor desejo quando pensam que os pobres pertencem a uma raça diferente da sua.

O argumento racial é uma das razões indicadas por Alesina et al. (2001) para explicar o porquê de as preferências por redistribuição serem menores nos Estados Unidos, dado que qualquer programa de transferência de renda irá favorecer desproporcionalmente AfroAmericanos, Hispânicos e outras raças minoritárias. A partir dessa premissa, os autores tentam realizar diferentes exames empíricos. No primeiro, examinam a heterogeneidade racial entre os países. Para isso, é construída uma variável a fim de capturar a fragmentação racial, mostrando uma correlação inversa de 0,66 com a redistribuição, como pode ser observado na Figura 1.

A Figura 1 mostra a tendência negativa, de diminuição do gasto social com o aumento do índice de Racial Fractionalization criado pelos autores. Um maior valor dessa variável significa uma maior heterogeneidade racial, o que está correlacionado com menores gastos sociais.

Os autores identificam que há uma inclinação a favor de políticas de bem-estar por parte daqueles com maiores níveis educacionais, e essa inclinação é mais presente nos moradores de grandes cidades. Porém, a variável mais relevante se refere à raça. Negros dedicam maior apoio à redistribuição do que brancos.

Dessa forma, Alesina et al. (2001) encontram uma forte correlação negativa entre a heterogeneidade racial e a disposição das pessoas a apoiarem maiores gastos sociais em bemestar. 


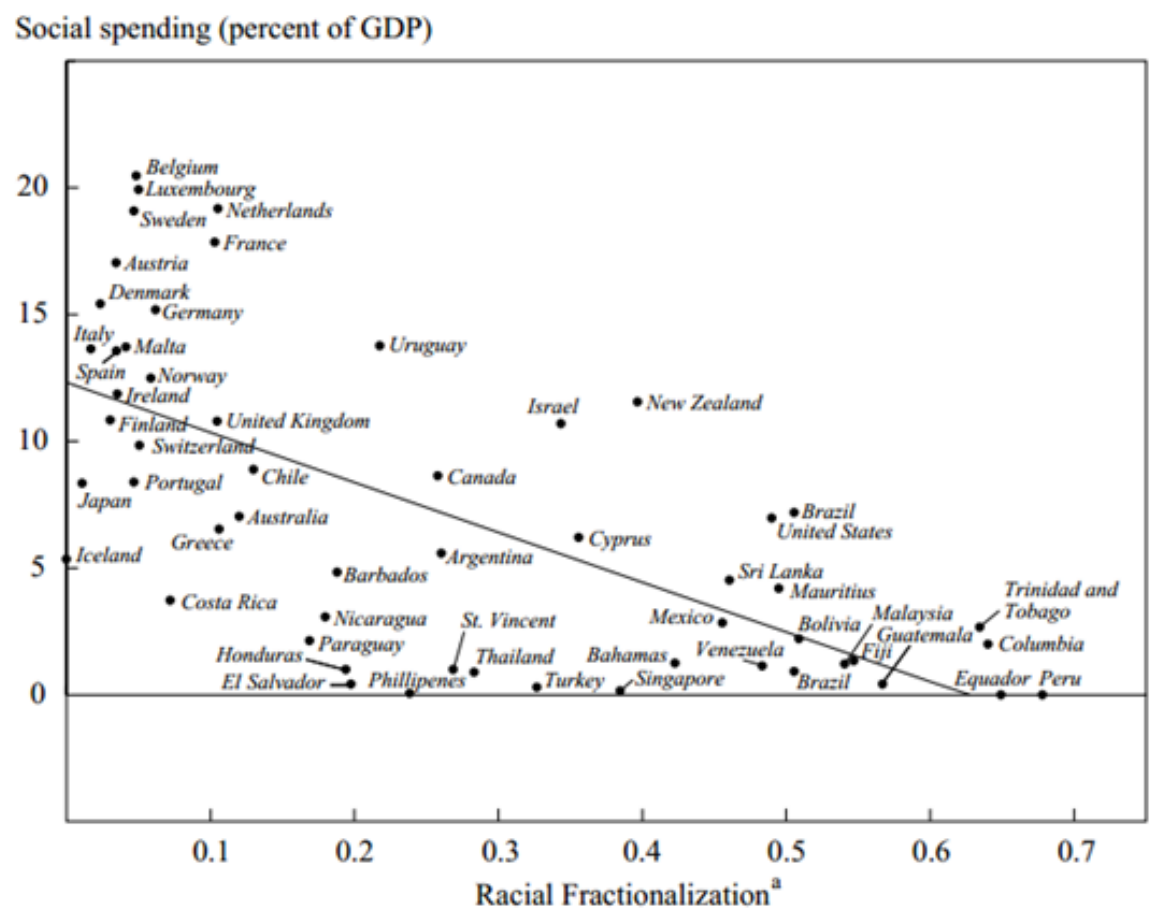

Figura 1. Gastos sociais e fragmentação racial Fonte: Reproduzido de Alesina et al. (2001)

A partir das verificações empíricas, Alesina et al. (2001) concluem que os menos afortunados deveriam apoiar mais políticas redistributivas. Porém, as pessoas levam em consideração o fato de que a mobilidade social pode fazer com que os pobres de hoje se tornem os ricos de amanhã. Os determinantes das preferências individuais por redistribuição estimados refletem essas considerações intertemporais.

De fato, o apoio por políticas redistributivas de um indivíduo é negativamente afetado pela expectativa de renda futura e pela probabilidade de superar uma linha que divide os que ganham dos que perdem com a redistribuição. Por outro lado, atitudes acerca da redistribuição não são afetadas por medidas genéricas de mobilidade que não capturem bem os ganhos e perdas relativos de políticas de redistribuição futuras.

Os autores também confirmam o efeito racial bem conhecido na literatura: após controlar para as características individuais, os brancos são mais avessos à redistribuição do que os negros.

Acerca das percepções sobre justiça, Alesina et al. (2011) encontraram que as pessoas que mais se opõe à intervenção em questões distributivas são aquelas que acreditam que a competição na sociedade é justa, isto é, que todos têm as mesmas oportunidades de melhorarem na vida.

De certo modo, esses indivíduos sentem que a mobilidade social é mais alta, menos o governo deve redistribuir: se a mobilidade é alta, e todos se beneficiam disso, então o mercado funciona como um determinante da distribuição de renda e o governo não deve interferir. Por outro lado, aqueles que acreditam que oportunidades não são iguais para todos, e que a desigualdade de renda também reflete desigualdade de oportunidades, não acreditam que a mobilidade social atue como um substituto para a intervenção do governo através de redistribuição. 
Os resultados de Alesina et al. (2001) sugerem que, até certo ponto, o público vê uma troca entre a oferta de iguais oportunidades e equalização das rendas, mas que esse grau de substituição depende das regras do jogo. Isso pode ter implicações políticas importantes ao avaliar o desejo de políticas redistributivas.

Assim, analisando as perspectivas econômicas, políticas e comportamentais, os autores concluem que as razões determinantes para os diferentes níveis de redistribuição verificados entre Estados Unidos e Europa estão relacionadas a três dimensões: diferenças nos sistemas políticos, crenças raciais e sociais sobre os pobres.

\section{MODELOS DE REDISTRIBUIÇÃO BASEADOS EM CRENÇAS SOCIAIS}

\subsection{MODELOS DE CRENÇAS SOCIAIS NA OCDE}

Estudos recentes têm buscado a explicação dos diferentes níveis de redistribuição nas sociedades através do papel das crenças sociais. Segundo esses autores, as diferenças em políticas redistributivas se devem principalmente a comportamentos contrastantes ou percepções individuais ao invés de variáveis políticas ou econômicas.

Alesina \& Angeletos (2005) oferecem uma investigação do papel das crenças na sorte ou esforço individual como determinantes da renda de cada pessoa, influenciando os níveis de gastos correntes com bem-estar. Os autores propõem que as sociedades estariam dispostas a corrigir as diferenças nas rendas individuais que se devem a sorte ou corrupção, mas não causadas pelo esforço.

Nesse novo modelo, sociedades com maiores níveis de crenças no papel da sorte em determinar a renda individual estariam mais propensas a apoiar políticas redistributivas do que aqueles em que a crença no esforço individual prevalece.

De acordo com a Figura 2, verifica-se uma correlação positiva de 0,44 entre as crenças individuais no papel da sorte como determinante da renda e os níveis de gastos sociais em cada país. A tendência é mais clara para países da OCDE, enquanto países da América Latina não se ajustam bem a linha de tendência, o que será explorado posteriormente por Figueiredo (2012).

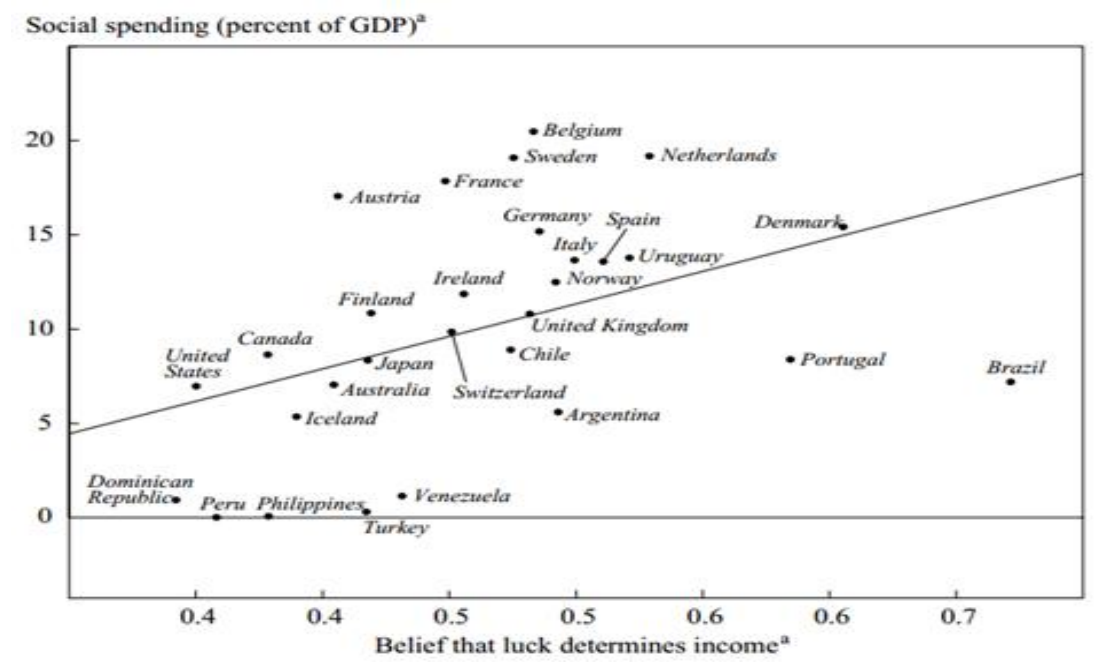

Figura 2. Relações entre gastos sociais e a crença de que sorte determina renda Fonte: Reproduzido de Alesina et al. (2001) 
Ainda, Alesina \& Angeletos (2005) argumentam que sociedades com maiores níveis de redistribuição são sociedades nas quais a sorte acaba por ser mais determinante na geração da renda individual, devido a maiores níveis de interferências no mercado e maiores níveis de corrupção. Reciprocamente, sociedades com menores níveis de distribuição são sociedades nas quais o esforço acaba por ter um papel determinante nas rendas.

Assim, as crenças sociais na sorte ou esforço são autorrealizáveis. O modelo mostra dois equilíbrios estáveis distintos. O primeiro é caracterizado por baixa taxação, alta desigualdade e baixa percepção de injustiça, representando os Estados Unidos (US), enquanto o segundo equilíbrio apresenta alta taxação, baixa desigualdade e alta percepção de injustiça, representando a média dos países da União Europeia (EU).

A Figura 3 representa a relação entre a taxação que os agentes antecipam ex-ante (eixo horizontal) e a taxação que a sociedade acha ótima ex-post (eixo vertical). A curva sólida representa uma economia na qual o efeito da sorte é moderado comparado ao talento e esforço. Um equilíbrio corresponde a qualquer intersecção dessa curva com a linha de $45^{\circ}$.

Segundo Alesina \& Angeletos (2005) há dois equilíbrios estáveis, um com baixa taxação, alta desigualdade e baixa injustiça, chamado de Equilíbrio US; e um com alta taxação, baixa desigualdade e alta injustiça, Equilíbrio EU.

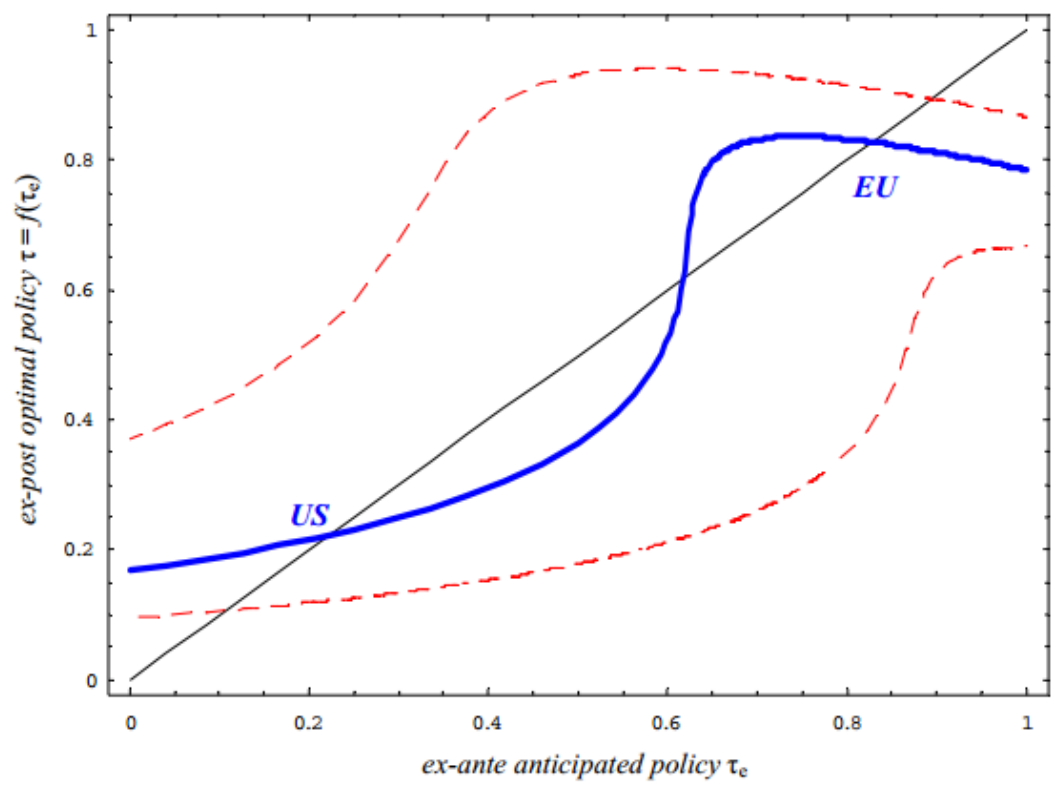

Figura 3. Equilíbrios múltiplos de taxação Fonte: Reproduzido de Alesina \& Angeletos (2005)

A linha curva pontilhada inferior representa uma economia onde o efeito percebido da sorte é muito pequeno, para o qual é adotado uma política de baixa taxação. A curva pontilhada superior representa uma economia na qual a percepção da sorte domina, apresentando assim uma política de alta taxação.

No ponto EU, a expectativa de altos impostos induz os agentes a exercerem pequenos esforços no primeiro período. Por sua vez, isso implica que a maior parte da heterogeneidade de renda se deve à sorte e faz com que o ótimo para a sociedade ex-post seja alcançado através de grandes programas redistributivos, assim confirmando as expectativas iniciais. 
No ponto US, a expectativa de baixos impostos induz os agentes a exercerem alto esforço, implicando que a variação de renda é principalmente atribuída à heterogeneidade de talento e esforço, o que, por sua vez, faz com que a baixa redistribuição seja autossustentável no processo político. Dessa forma, o nível de desigualdade (como mensurado pela variância total da renda) é menor em EU, mas, segundo os autores, a decomposição da desigualdade é mais justa em US, o que explica o porquê de mais desigualdade ser consistente com menos impostos.

Bénabou \& Tirole (2006) revisitam o modelo desenvolvido por Alesina \& Angeletos (2005) e o refinam com a inclusão da crença em um mundo justo. Os autores examinam as implicações que acreditar em um mundo justo tem em diferentes esferas da sociedade, assim como as políticas redistributivas e a percepção sobre os pobres. Eles também encontram dois equilíbrios, um com menor taxação e crenças na justiça generalizadas, chamado de "Equilíbrio Americano", e outro com um Estado de Bem-Estar Social mais extensivo e maior pessimismo sobre a justiça, chamado então de "Equilíbrio Europeu".

A diferença entre os modelos reside nas razões encontradas para cada equilíbrio. Para Bénabou \& Tirole (2006), o Equilíbrio Americano é escolhido devido à influência da ideia do American Dream, que inclui a crença em um mundo justo como endogenamente uma ideologia compartilhada nos Estados Unidos.

A fim de compreender o apoio por redistribuição das classes médias e baixas quando a classe mais alta é desproporcionalmente favorecida, Ku \& Salmon (2012) realizaram algumas experiências e chegaram a novas conclusões.

É particularmente interessante a proposta que quando os indivíduos em situação de desvantagem se veem com a mesma identidade daqueles em melhores condições, eles tornamse mais tolerantes sobre a desigualdade de renda entre eles. Isso está relacionado a hipótese de preconceito racial testada por Alesina et al. (2001) no modelo comportamental anteriormente examinado.

Além disso, $\mathrm{Ku} \&$ Salmon (2012) verificam que sujeitos são geralmente mais favoráveis a redistribuição para aqueles que pertencem ao mesmo grupo racial. Dessa forma, políticas de crescimento pró-pobre podem ser menos apoiadas nos Estados Unidos do que na Europa graças a visões mais meritocráticas e maior heterogeneidade racial nos Estados Unidos.

A partir dos modelos desenvolvidos para explicar as diferenças nos níveis de redistribuição entre Estados Unidos e Europa, e na OCDE como um todo, autores desenvolveram modelos para explicar os níveis de redistribuição verificados na América Latina e no Brasil.

\subsection{REDISTRIBUIÇÃO NO BRASIL \& AMÉRICA LATINA}

Para compreender a realidade dos países da América Latina é necessário um olhar mais próximo nas variáveis que, em alguns casos, diferem significativamente das verificadas em países desenvolvidos. A base de dados do Latinobarômetro, uma organização inspirada pela World Values Survey que elabora questionários com perguntas voltadas ao público da América Latina oferece alguns insights. 
Uma das perguntas presentes na survey visa verificar se a pessoa acha que nos 12 meses seguintes à pesquisa a sua situação econômica ou de sua família será muito melhor, um pouco melhor, igual, um pouco pior, ou muito pior do que agora. Considerando as respostas "muito melhor" e "um pouco melhor" como uma visão otimista sobre o futuro - e mobilidade social - o Brasil é o país mais otimista da América Latina, com 64\% dos respondentes acreditando em uma melhor situação econômica futura.

A evidência empírica sobre crenças em mobilidade social no Brasil, de acordo com o modelo, deveria indicar menor apoio para políticas de redistribuição de renda em relação aos países com menores expectativas futuras, mas no Brasil convivem a expectativa otimista de mobilidade social e o alto índice de redistribuição de renda.

De acordo com o modelo de Alesina \& Angeletos (2005) analisado em seção anterior, as previsões são de que indivíduos com expectativas de maiores rendas futuras seriam menos favoráveis a políticas de redistribuição de renda. As evidências empíricas, porém, não confirmaram essa previsão.

As variáveis indicadas pelos autores como crenças determinantes nos níveis de redistribuição de renda podem ser analisadas comparativamente a partir da World Values Survey. São exibidos na tabela 1 os resultados encontrados para as seguintes questões: se a pessoa acredita que os pobres podem ou não escapar da pobreza, se os pobres são preguiçosos, ou se é a sorte ou o esforço o mais importante na determinação da renda.

A diferença média da proporção de respondentes que se identificam como de Esquerda é menor entre Brasil e União Europeia. O Brasil, com uma porcentagem de 26,8\% de pessoas de Esquerda, dista apenas 3,2\% pontos dos resultados Europeus de 30\%, enquanto se distancia em 9,8\% pontos da proporção de pessoas de Esquerda dos Estados Unidos, de 17\%.

É importante notar a alta proporção de respondentes que acreditam que os pobres estão presos na pobreza no Brasil. O resultado de 71,3\% é superior ao resultado Europeu, de $60 \%$, em $11,3 \%$ pontos, e muito superior ao dos Estados Unidos, de apenas 29\%, distando assim $42,3 \%$ pontos.

\begin{tabular}{lccc}
\hline & Brasil & UE & EUA \\
\hline Identificam-se como de Esquerda & 26,8 & 30 & 17 \\
Acreditam que pobres estão presos na pobreza & $\mathbf{7 1 , 3}$ & $\mathbf{6 0}$ & $\mathbf{2 9}$ \\
Percentual que são de Esquerda & 27,6 & 34 & 26 \\
Não acreditam que pobres estão presos na pobreza & 28,7 & 40 & 71 \\
Percentual que são de Esquerda & 24,7 & 27 & 14 \\
Acreditam que sorte determina a renda & $\mathbf{7 5 , 1}$ & $\mathbf{5 4}$ & $\mathbf{3 0}$ \\
Percentual que são de Esquerda & 26,6 & 35 & 18 \\
Não acreditam que sorte determina a renda & 24,9 & 46 & 70 \\
Percentual que são de Esquerda & 27,2 & 25 & 16 \\
Acreditam que pobres são preguiçosos & $\mathbf{2 0 , 6}$ & $\mathbf{2 6}$ & $\mathbf{6 0}$ \\
Percentual que são de Esquerda & 23,3 & 23 & 11 \\
Não acreditam que pobres são preguiçosos & 79,4 & 74 & 40 \\
Percentual que são de Esquerda & 27,6 & 34 & 25 \\
\hline Fonte: Elaborado pelo autor a partir da base de dados do World Values Survev & & \\
Base de dados para EU e EUA: 1981-1997 & & & \\
Base de dados para Brasil: 1997. & & &
\end{tabular}

Tabela 1. Relação entre orientação política e crenças sobre os pobres (\%) 
A tabela 1 também apresenta a relação entre essas variáveis e a identificação como posição política de Esquerda. A proporção de pessoas que são de Esquerda e responderam que os pobres estão presos na pobreza é de $27,6 \%$, com uma proporção muito semelhante das pessoas de Esquerda que não acreditam que os pobres estão presos na pobreza, de 24,7\%. Esse resultado difere do resultado dos Estados Unidos, no qual pode-se perceber uma forte conexão entre as pessoas que se descrevem como de Esquerda e acreditam que os pobres estão presos na pobreza. Nos Estados Unidos, 26\% das pessoas que acreditam que os pobres estão presos na pobreza são de Esquerda, porém apenas $14 \%$ das pessoas que não acreditam são de Esquerda. A variável Esquerda para o Brasil não é determinante na crença de que as pessoas estão presas na pobreza ou não.

O papel da sorte na crença dos brasileiros se apresenta muito elevado em relação à Europa e Estados Unidos. No Brasil, $75,1 \%$ das pessoas acreditam que a sorte é fator determinante da renda, comparado a 54\% na União Europeia e apenas 30\% nos Estados Unidos.

Novamente, não há diferenças contrastantes para o Brasil entre a relação de pessoas que de Esquerda que acreditam na sorte, 26,6\%, e as pessoas de Esquerda que não acreditam que a sorte determina renda, 27,2\%. Para os Estados Unidos a diferença é de apenas $2 \%$ pontos, e para a Europa, apesar da diferença de $10 \%$ nas pessoas de Esquerda que acreditam no esforço ou na sorte, Alesina et al. (2001) chega à conclusão de que não há diferença nas crenças de sorte ou esforço para as pessoas de Esquerda nos Estados Unidos e na União Europeia. A mesma conclusão é válida para o Brasil.

Analisando a crença das pessoas sobre se os pobres são preguiçosos, o resultado brasileiro, de 20,6\%, ficando abaixo em 5,4 p.p. do resultado Europeu, de 26\%. Pode-se afirmar que os resultados brasileiros são muito semelhantes aos resultados europeus, dado que a crença brasileira se distancia em 39,4\% pontos da crença de que pobres são preguiçosos nos Estados Unidos. Entretanto, a orientação de Esquerda não se mostra significante na crença dos brasileiros sobre preguiça e pobreza, com uma diferença de apenas $4,3 \%$ na proporção de pessoas de Esquerda que acreditam que os pobres são preguiçosos e que acreditam o contrário. Essa variação é menor do que na Europa, 11\%, e nos Estados Unidos, $14 \%$.

Assim, a partir destes números pode-se perceber que, em geral, os brasileiros acreditam fortemente que os pobres estão presos na pobreza e no papel da sorte como determinante da renda. Por outro lado, não acreditam que pobres são preguiçosos e a orientação política de Esquerda não difere proporcionalmente entre as crenças.

\subsection{IGUALDADE DE OPORTUNIDADES NA AMÉRICA LATINA}

As hipóteses dos modelos anteriormente explorados foram desenvolvidas para os Estados Unidos e Europa. A realidade do Brasil e da América Latina é distinta, e talvez também o é o modelo que explique as relações entre crenças sociais sobre os pobres e políticas de redistribuição de renda. Nessa linha, Figueiredo (2012) desenvolve um modelo inspirado pelo de Alesina \& Angeletos (2005) a fim de explicar as preferências por redistribuição nos países da América Latina.

Com novos fundamentos empíricos, Figueiredo (2012) descartou a influência das crenças meritocráticas nos níveis de redistribuição de renda nos países da América Latina. Ao 
invés, propôs a validade de uma nova regra de justiça que considera as percepções na igualdade de oportunidades. Tal regra se aplicaria principalmente a países da América Latina e seria justificada pelas percepções de desigualdade como um todo ao invés de seus componentes.

Assim, a alta desigualdade no continente, somada às percepções de oportunidades desiguais, levariam os países a estabelecer amplas políticas redistributivas - correspondendo a um equilíbrio caracterizados pela percepção de injustiça em termos de igualdade de oportunidade e alta taxação.

Figueiredo (2012) encontrou que, diferentemente dos resultados obtidos por Alesina et al. (2001), as estimativas para os países da América Latina indicam que a percepção de injustiça baseada no mérito não tem um impacto no bem-estar individual. Segundo o autor, apesar dos habitantes desses países considerarem a sorte como um fator fundamental para os resultados econômicos individuais, isso não é um determinante para suas preferências por redistribuição.

O autor propôs uma nova forma de mensurar a demanda por redistribuição em cada país, incorporando a crença das pessoas na igualdade de oportunidades. O papel do esforço na determinação da renda nos países da América Latina não tem tanto peso quando se colocam disparidades significativas nas oportunidades de sair da pobreza ou de melhorar de vida. Para isso, consultou a base Latinobarometro, uma survey inspirada na World Values Survey, porém direcionada e aplicada apenas a países da América Latina. Perguntou-se se o sistema econômico do país oferece oportunidades iguais para todos, ou então, que as oportunidades de escapar da pobreza não são dadas para todos.

Figueiredo (2012) utilizou o percentual de pessoas que acreditam na desigualdade de oportunidades de escapar da pobreza como um proxy para a nova regra de justiça. A Figura 4 apresenta a relação positiva entre a porcentagem daqueles que responderam que o país não oferece oportunidades iguais para todos e os gastos sociais de seu país.

A tendência positiva é clara. A porcentagem daqueles que acreditam que o país não oferece igualdade de oportunidades está diretamente relacionada com um maior gasto social no país. Assim, Figueiredo (2012) incorporou no modelo de Alesina et al. (2001) o componente de crença na igualdade de oportunidades como uma nova regra para a demanda por redistribuição.

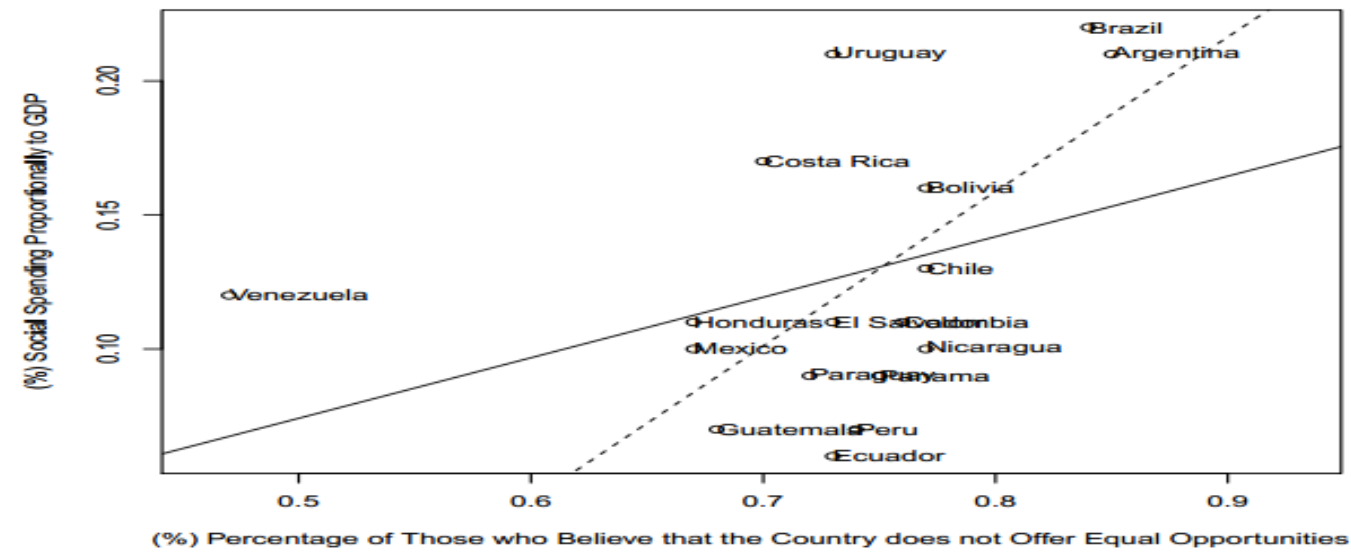

Figura 4. Relação entre gastos sociais e descrença em igualdade de oportunidades Fonte: Reproduzido de Figueiredo (2012) 
Ao incorporar esse elemento, o autor encontrou um equilíbrio próximo ao equilíbrio da Europa, mas em um nível menor. Assim, Figueiredo (2012) concluiu que a demanda por justiça, baseada na desigualdade como um todo e não em sua composição, leva as economias da América Latina a adotar altos níveis de impostos e redistribuição, apenas inferiores aos níveis praticados nas políticas de Bem-Estar Social da Europa.

\section{4 - CONSIDERAÇÕES FINAIS}

Os modelos que buscam explicar os determinantes da redistribuição de renda em um país passaram por uma evolução nas últimas décadas. O trabalho de Meltzer \& Richard (1981) trouxe fundamentações importantes a partir da ideia do eleitor decisivo que, através da regra de votação da maioria, torna-se o eleitor de renda mediana da sociedade.

Segundo os autores, esse eleitor demandará maior redistribuição quando a sua renda estiver abaixo da renda média da sociedade, o que o colocaria na posição de receptor de renda. Caso contrário, demandaria uma menor distribuição de renda, estando na posição de doador de renda. Assim, os autores afirmam que políticas de redistribuição de renda seriam mais demandadas em sociedades com maiores desigualdades de renda.

As conclusões, porém, não vão de encontro com os resultados empíricos obtidos por outros autores. Sociedades com maiores desigualdades de renda não necessariamente representam sociedades com maiores níveis de gastos sociais. Analisando o caso da Europa e dos Estados Unidos, Alesina et al. (2001) buscam formular novas explicações.

Das hipóteses políticas, econômicas e comportamentais analisadas pelos autores, as explicações mais significativas concernem o sistema político de cada país, que impede ou estimula o desenvolvimento de um estado de Bem-Estar Social, a variável de fragmentação racial, cuja maior heterogeneidade significa menores demandas por redistribuição, e o papel das crenças sociais.

Alesina \& Glaeser (2005) examinaram mais atentamente o papel das crenças sociais na determinação dos níveis de redistribuição de renda. Dados de surveys (World Values Survey, General Social Survey e Latinobarometro) revelaram que a crença dos indivíduos de que a sorte tem um papel fundamental na renda, indicando uma menor crença na recompensa pelo esforço, mostrou-se significativa para explicar a demanda por gastos sociais nos países desenvolvidos da OCDE.

Para os países de América Latina, o papel da sorte e do esforço não é tão claro na determinação da renda. Figueiredo (2012) construiu um modelo que incorpora a crença das pessoas sobre a igualdade de oportunidades no seu país. Quando os indivíduos acreditam que seu país não oferece oportunidades de melhorar na vida iguais para todos, demandam um maior nível de redistribuição de renda a fim de compensar o infortúnio dos menos favorecidos. 


\section{REFERÊNCIAS BIBLIOGRÁFICAS}

ALESINA, Alberto; ANGELETOS, George-Marios. Fairness and redistribution: US vs. Europe. American Economic Review, v. 95, 2005.

ALESINA, Alberto; GLAESER, Edward Ludwig. Fighting poverty in the US and Europe: A world of difference. Oxford University Press, 2004.

ALESINA, Alberto; GLAESER, Edward; SACERDOTE, Bruce. Why doesn't the US have a European-style welfare system?. National bureau of economic research, 2001.

BECKER, Gary S. The economics of discrimination. The American Catholic Sociological Review, v. 18, p. $276,1957$.

BENABOU, Roland; TIROLE, Jean. Belief in a just world and redistributive politics. National Bureau of Economic Research, 2005.

FIGUEIREDO, Erik Alencar de. Fairness and Redistribution: the Case of Latin American Countries. Programa de Pós-Graduação em Economia-PPGE, Universidade Federal da Paraíba, 2012.

GOTTSCHALK, Peter; SPOLAORE, Enrico. On the evaluation of economic mobility. The Review of Economic Studies, v. 69, n. 1, p. 191-208, 2002.

KU, Hyejin; SALMON, Timothy C. The incentive effects of inequality: An experimental investigation. Southern Economic Journal, v. 79, n. 1, p. 46-70, 2012.

LATINOBARÓMETRO, Cooperación. Informe Latinobarómetro 2005, 1995-2005. Diez años de opinión pública, Santiago de Chile, p. 64, 2005.

MILESI-FERRETTI, Gian Maria; PEROTTI, Roberto; ROSTAGNO, Massimo. Electoral systems and public spending. Quarterly Journal of Economics, p. 609-657, 2002.

PERSSON, Torsten; ROLAND, Gerard; TABELLINI, Guido. Comparative politics and public finance. Journal of political Economy, v. 108, n. 6, p. 1121-1161, 2000.

SKOCPOL, Theda. Protecting soldiers and mothers: The political origins of social policy in the United States. Cambridge: Harvard University Press, 1992.

WORLD ECONOMIC FORUM. The Global Competitiveness Report 1996. Geneva: World Economic Forum, 1996.

WORLD VALUES SURVEY, Inter-university Consortium for Political and Social Research, 2015. 